\title{
RESEARCH ON THE STATIC CHARACTERISTICS OF AIR DRIVEN GAS BOOSTER
}

\author{
Haitao WANG, Wei XIONG and Xu WANG \\ Transportation and Logistics Engineering College; Dalian Maritime University \\ 1 Linghai Road, Dalian, 116026, China \\ (E-mail:wht810@vip.sina.com)
}

\begin{abstract}
The process that the low pressure gas in two gas tanks were reclaimed through air driven gas booster to one empty high pressure tank has been studied in this paper. Calculation formulae of performance parameters of the gas booster such as the inlet pressure, outlet pressure, volume of discharge and intake, air consumption in per cycle were obtained, and the change tendency of these performance parameters during its isothermal quasi-static processes was analyzed and several static characteristics and structural parameters that influences the booster's working performance were found out. The importance of dead volume and the way to raise the booster's efficiency was stated. The results are helpful for model selection, design and application of gas boosters.
\end{abstract}

\section{KEY WORDS}

Air driven gas booster, Static characteristics, Compression ratio, Dead volume

\section{NOMENCLATURE}
$A$ : Area of air driving piston
$a:$ Area of gas piston
$a_{0}:$ Cross sectional area of piston rod
$P_{\mathrm{a}}:$ Standard atmosphere pressure
$P_{\mathrm{D}}: \quad$ Driving air pressure
$P_{\mathrm{O} k}$ : Outlet air pressure of the $k$-th cycle
$P_{\mathrm{S} k}$ : Inlet air pressure of the $k$-th cycle
$S:$ Stroke of piston
$V_{0}:$ Dead volume
$V_{\mathrm{C}}$ : Total volume of high pressure chamber
$V_{\mathrm{E}}:$ Air consumption volume per cycle
$V_{\mathrm{O} k}$ : Gas discharge volume of the $k$-th cycle
$V_{\mathrm{S} k}$ : Gas suction volume of the $k$-th cycle
$V_{\text {in }}$ : Total volume before inlet check valve
$V_{\text {ou }}$ : Total volume behind outlet check valve
$i$ : Pressure ratio
$i_{\mathrm{C} k}: \quad$ Compressed ratio of the $k$-th cycle

\section{INTRODUCTION}

High pressure compressed air is usually needed in many industrial fields [4]. Air driven gas booster with the advantages of using low pressure air as power, supercharging efficiently, structured compactly, being portable and explosion-proof, reducing the cost and installing spaces to a great extent, has been widely used in many fields such as low pressure gas reclaiming, high-pressure gas injection, gas pressure testing and leak testing [1]. However, the tendency of pneumatic technology to high pressure has raised many new requirements to booster's structure and performance, such as higher pressure ratio and charging efficiency and more compact structure. Based on the working principle and structure of single acting gas booster, this paper has studied parameter factors that influences the booster's working performance and analyzed the booster's static characteristics. 


\section{WORKING PRINCIPLE OF AIR DRIVEN GAS BOOSTER}

Air driven gas booster works according to PASCAL'S LAW as Figure 1 shows [3]. The large-area air driving piston 5 in the air driving chamber 4 is connected with the piston rod to the small-area gas piston 7 located in the high pressure chamber 6 . Thus by using the area difference between the tow pistons, the purpose to compress the gas in the high pressure chamber with the low pressure air as power acting on the large-area piston is realized.

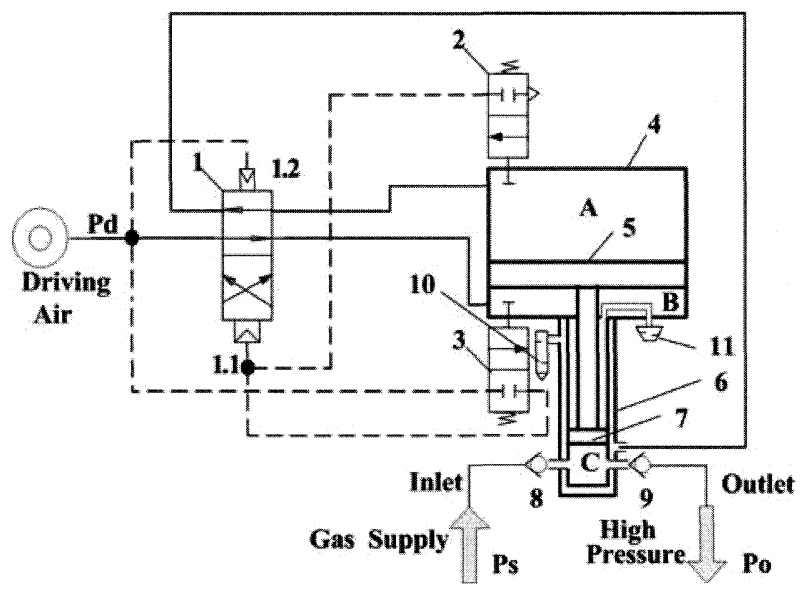

Figure 1 Working principle of air driven gas booster

Based on the static force balance principle,

$$
P_{\mathrm{O}}=\frac{A}{a} \cdot P_{\mathrm{D}}=i \cdot P_{\mathrm{D}}
$$

$i=A / a$ is defined as pressure ratio. When $A>a, P_{\mathrm{O}}>P_{\mathrm{D}}$ [3]. The larger the area difference is, the more obvious the supercharging effect becomes.

The continuous operation is achieved by the cycling control valve 1 whose spool leads the drive air alternately on the upper and bottom surface of the air piston and is piloted through the upper pilot valve 2 and down pilot valve 3 which are mechanically actuated through the air drive piston in its end positions [1]. The exhaust air from the driving chamber is lead to the peripheral barrel to cool the high pressure gas chamber [2].

\section{PARAMETERS CALCULATION AND ANALYSIS OF STATIC CHARACTERISTICS}

The low pressure gas recovery process is studied as shown in Figure 2. At the beginning of recovery, low pressure gas is directly charged to high pressure tank through inlet and outlet check valves as the existence of the pressure difference between the tow tanks, until the pressure of low and high tanks becomes balanced. Then gas booster works. The gas booster works as the sequence of suction, compression and exhaust. Now study on the k-th cycle.

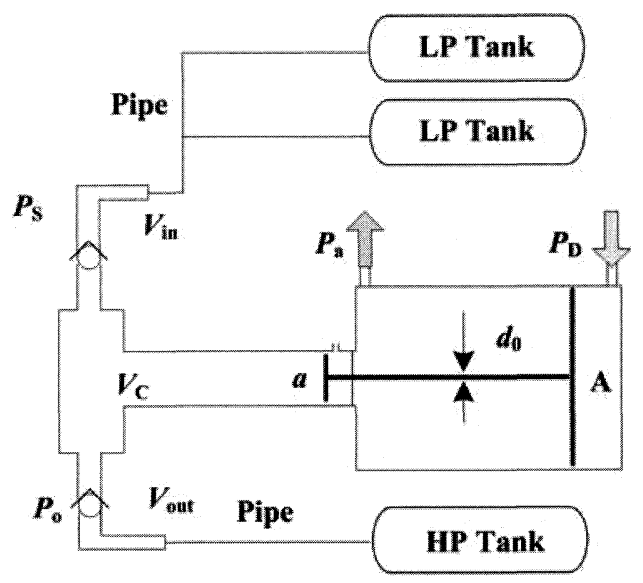

Figure 2 Low pressure gas reclaiming

Inlet and Outlet Pressure $\boldsymbol{P}_{\mathrm{S} \boldsymbol{k}}$ and $\boldsymbol{P}_{\mathrm{O} \boldsymbol{k}}$

According to law of mass conservation, when the $\mathrm{k}$ time cycle ends, there are the equations below:

$$
\begin{gathered}
P_{\mathrm{S} k}+V_{\text {out }} P_{\mathrm{O} k-1}=\left(V_{0}+V_{\text {out }}\right) P_{\mathrm{O} k} \\
V_{0} P_{\mathrm{O} k-1}+V_{\text {in }} P_{\mathrm{S} k-1}=\left(V_{\text {in }}+V_{\mathrm{C}}\right) P_{\mathrm{S} k}
\end{gathered}
$$

The inlet and outlet pressure of the $k$-th cycle is obtained

$$
\begin{aligned}
& P_{\mathrm{O} k}=\frac{V_{\mathrm{C}}}{V_{0}+V_{\text {out }}} P_{\mathrm{S} k}+\frac{V_{\text {out }}}{V_{0}+V_{\text {out }}} P_{\mathrm{O} k-1} \\
& P_{\mathrm{S} k}=\frac{V_{\text {in }}}{V_{\text {in }}+V_{\mathrm{C}}} P_{\mathrm{S} k-1}+\frac{V_{0}}{V_{\text {in }}+V_{\mathrm{C}}} P_{\mathrm{O} k-1}
\end{aligned}
$$

The change of $P_{\mathrm{O} k}$ and $P_{\mathrm{S} k}$ with the increase of working cycle is obtained recursively as shown in Figure 3. Figure 3 shows that with the increasing of working cycles both curves changes greatly on earlier stage, and change slowly on middle-later stage, and on the later stage when the cycle times reaches up to a certain value, both curves nearly keep stable.

Compressed ratio $i_{\mathrm{C}}$ is defined as follows [1]:

$$
i_{\mathrm{C}}=P_{\mathrm{O}} / P_{\mathrm{S}}
$$




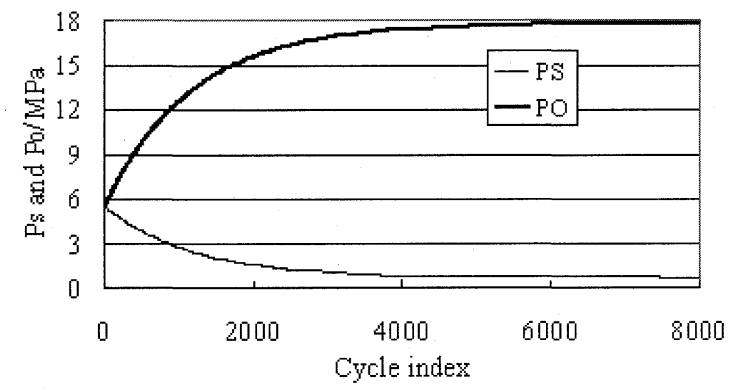

Figure $3 P_{\mathrm{O}}$ and $P_{\mathrm{S}}$ with the change of cycle

$i_{\mathrm{C}}$ indicates the compressed degree of low gas .It is a variable,while pressure ratio $i$ is a fixed value which shows the maximum ability of compression of the booster. The curve of $i_{\mathrm{C}}$ is shown in Figure 4 below, from which we know that $i_{\mathrm{C}}$ increases gradually, and keeps stable on the later stage.

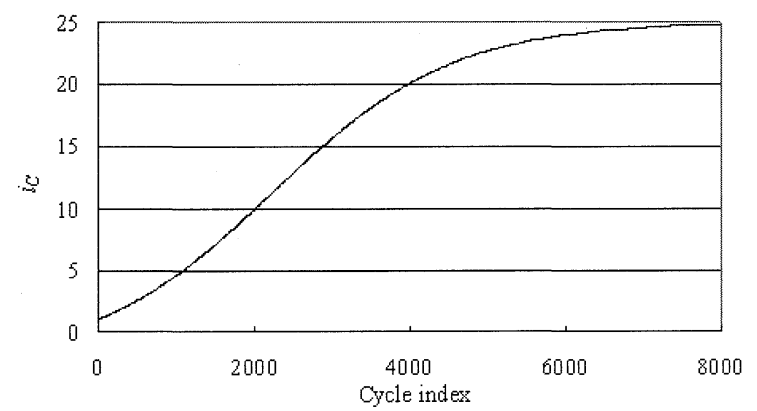

Figure $4 i_{\mathrm{C}}$ with the change of cycle

\section{Gas Discharge and Intake Volume $\boldsymbol{V}_{\mathrm{O} \boldsymbol{k}}$ and $\boldsymbol{V}_{\mathrm{S} \boldsymbol{k}}$}

Gas discharge volume of the $k$-th cycle is equal to the standard difference volume of gas in high pressure chamber before and after the compression, so gas discharge volume of the $k$-th cycle is

$$
V_{\mathrm{C} k}=\frac{P_{\mathrm{S} k}}{P_{\mathrm{a}}} V_{\mathrm{C}}-\frac{P_{\mathrm{O} k}}{P_{\mathrm{a}}} V_{0}
$$

Formula 7 can also be expressed as follows.

$$
V_{\mathrm{C} k}=\frac{P_{\mathrm{S} k}}{P_{\mathrm{a}}}\left(V_{\mathrm{C}}-i_{\mathrm{C} k} V_{0}\right)
$$

The change of $V_{\mathrm{C} k}$ with $i_{\mathrm{C} k}$ is shown in Figure 6. With the increase of $i_{\mathrm{Ck}}, V_{\mathrm{Ck}}$ reduces gradually, until to zero. And when $i_{C k}$ gets to a certain value, the discharged gas becomes very little, and the working efficiency of gas booster is very low.

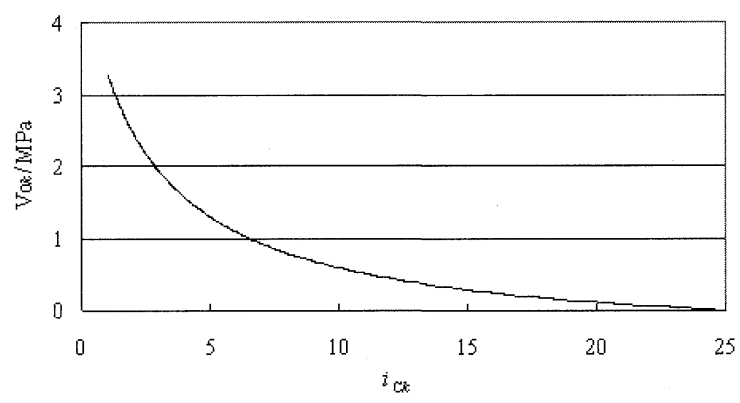

Figure $6 V_{C k}$ with the change of $i_{C k}$

The $i_{\mathrm{C}}$ when $V_{\mathrm{C}}$ is zero is defined as the maximum compressed ratio $i_{\text {Cmax }}$.

$$
i_{\text {Cmax }}=\frac{V_{\mathrm{C}}}{V_{0}}
$$

The dimensions of $V_{0}$ and $V_{\mathrm{C}}$ have been decided when the booster was designed, after which the booster's maximum compressed ratio was determined. So when designing, if higher compressed ratio is wanted, reducing $V_{0}$ is feasible. For example, if the expected $i_{\text {Cmax }}$ is $25: 1, V_{0}$ must be less than $4 \%$ of $V_{\mathrm{C}}$.

Intake gas charge volume of the $k$-th cycle is equal to the standard difference volume of gas in high pressure chamber before and after suction, so intake gas charge volume of the $k$-th cycle is

$$
V_{\mathrm{S} k}=\frac{P_{\mathrm{S} k}}{P_{\mathrm{a}}} V_{\mathrm{C}}-\frac{P_{\mathrm{O} k-1}}{P_{\mathrm{a}}} V_{0}
$$

$V_{\mathrm{S} k}$ has similar change law with $V_{\mathrm{O} k}$.

\section{Air Consumption Volume Per Cycle $V_{E}$}

The total air consume volume of the $k$-th cycle is equal to the sum of the air consume volume of the suction and compression stroke. So the air consumption volume of one cycle is

$$
V_{\mathrm{E}}=\left(2 A-a_{0}\right) \frac{P_{\mathrm{D}}}{P_{\mathrm{a}}}
$$

Formula 11 shows the air consume volume per cycle is a fixed value. On the later stage, the outlet pressure increases very slowly while the piston is still moving under the push of driving air, so lots of driving air is wasted. In addition, when model selecting; the maximum compressed ratio of the booster to be selected 
should be bigger than the one needed in practical application, in order to save driving air and to limit the charging time to acceptable range.

\section{CONCLUSIONS}

Through the calculation and analysis above, the main structural parameters that influence the static characteristics of gas booster, the formulae of boater's performance parameters and its static characteristics combined with lots of graphs were obtained.

The main structural parameters include area of air driving piston $A$, area of gas piston $a$, cross sectional area of link rod $a_{0}$, stroke of piston $S$ and dead volume $V_{0}$. The dead volume $V_{0}$ is proved having great influence on the booster's static characteristics, and its dimension should be determined with discretion when designing. In addition, on the process of charging, the outlet pressure increases, inlet pressure reduces, both gas intake and discharge volume decreases, air consumption keeps constant cycle by cycle, and as on the later stage the growth rate of outlet pressure is very low and , it is not recommended to keep the booster working in this case for long time.

\section{REFERENCES}

1. MAXIMATOR Sample Manual, USA, 2008, pp.11.

2. HASKEL Sample Manual, USA, 2008, pp.2-4.

3. Jiding Shi, Automatic oil supply air piston pump driven by pneumatic (Chinese), Technology Equipment Department of Second Automobile, 2004, pp.1.

4. Technology of Compressor (Chinese), China, 2006. 